\title{
Population levels of wellbeing and the association with social capital
}

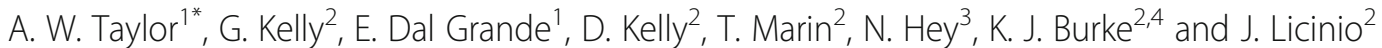

\begin{abstract}
Background: This research investigates wellbeing at the population level across demographic, social and health indicators and assesses the association between wellbeing and social capital.

Method: Data from a South Australian monthly chronic disease/risk factor surveillance system of randomly selected adults (mean age 48.7 years; range 16-99) from 2014/5 $(n=5551)$ were used. Univariable analyses compared wellbeing/social capital indicators, socio-demographic, risk factors and chronic conditions. Multi-nominal logistic regression modelling, adjusting for multiple covariates was used to simultaneously estimate odds ratios for good wellbeing (reference category) versus neither good nor poor, and good wellbeing versus poor wellbeing.
\end{abstract}

Results: $48.6 \%$ were male, mean age 48.7 (sd 18.3), 54.3\% scored well on all four of the wellbeing indicators, and positive social capital indicators ranged from $93.1 \%$ for safety to $50.8 \%$ for control over decisions. The higher level of social capital corresponded with the good wellbeing category. Modeling showed higher odds ratios for all social capital variables for the lowest level of wellbeing. These higher odds ratios remained after adjusting for confounders.

Conclusions: The relationship between wellbeing, resilience and social capital highlights areas for increased policy focus.

Keywords: Wellbeing, Social capital, Australia, Population

\section{Background}

Wellbeing and social capital are two dissociable but connected measureable attributes of individuals and communities. Understanding the role of social capital in building and strengthening wellbeing at the population level is an important consideration when aiming for best possible experience and functioning of the population [1].

The benefits of positive wellbeing have been shown to be associated with improved mental and physical health and overall enhanced quality of life [2-4]. An important notion within the positive wellbeing concept is resilience, broadly defined as the ability to bounce-back from negative events $[4,5]$. Resilience is also defined as the ability to capitalize on opportunity [6]. Large-scale/ small-time, minor/major adverse events or catastrophes occur in our daily lives and individuals and populations also have to deal with stress in times of economic downturns or social turmoil [7]. Developing personal skills to

\footnotetext{
*Correspondence: Anne.taylor@adelaide.edu.au

${ }^{1}$ Population Research \& Outcome Studies, Discipline of Medicine, The

University of Adelaide, Adelaide, South Australia, Australia

Full list of author information is available at the end of the article
}

overcome negative events in times of stress by increasing levels of resilience can assist individuals and communities to succeed in an environment that can be typified by change, insecurity and volatility [8]. Dynamic economic circumstances also require a flexible approach to employment and the ability to retrain or seize opportunity.

Social capital, broadly defined as connectedness within and between populations, and the quality and quantity of social relations within that population [9], is a multidisciplinary and multi-faceted, well researched area that encompasses social networks, trust, reciprocity and support $[4,9]$. 'Bonding' social capital is often used to describe the social relationship between individuals while 'bridging' social capital is seen as that between groups [4]. Although the definition of social capital is contested [7], it is acknowledged that social capital operating at both the micro and macro levels of society is related to health outcomes [1,9-11]. The debate regarding definition and measurement of social capital is not the focus of this paper; rather we aim to assess the association between 
social capital and wellbeing and resilience to provide additional explanatory factors [12].

While many governments have incorporated goals and targets into their portfolios often these are dominated by economic and demographic metrics. South Australia has embraced a state-wide approach to building, embedding and researching wellbeing and resilience. This strategy aims to increase the state's population level of positive wellbeing with an overall aim of assisting the society to thrive by measuring and building its level of resilience. As such, initiatives within schools, workplaces and communities have been introduced. Questions to assess the level of the wellbeing of the population have been incorporated into the South Australian government's monthly risk factor and chronic disease surveillance system [13] so that the subjective wellbeing at population and subpopulation level, can be monitored over time. As argued by others, measuring and assessing wellbeing is crucial for assessing the effectiveness of health promotion and population health wellness-orientated endeavours and initiatives [14, 15].

Research has shown that social capital is an important aspect of resilience following major disasters or large scale crisis [7]. Exploring the relationship between social capital, wellbeing and resilience in a community without a natural disaster or large scale acute event, provides policy makers and decision makers evidence, and an additional tool, to effect change to assist in the development of policy interventions to increase general wellbeing in the community [16].

Our aim therefore is to detail the levels of wellbeing at the population level in South Australia by a range of demographic, social, economic and health indicators and to assess the association between wellbeing and measures of social capital using models with the data adjusted for known confounders.

\section{Methods}

The data for these analyses were obtained from the South Australian Monitoring and Surveillance System (SAMSS), a monthly chronic disease and risk factor surveillance system of randomly selected persons, established in July 2002 [17]. All households in SA with a telephone number listed in the Electronic White Pages (EWP) are eligible for selection in the sample. A letter introducing SAMSS is sent to the household of each selected telephone number. Within each household the person who had a birthday last is selected for interview. There is no replacement for non-contactable persons. Data are collected by a contracted agency using Computer Assisted Telephone Interviewing (CATI) and interviews are conducted in English. Informed consent was obtained before the start of the interview. Detailed SAMSS methodology has been published elsewhere [13, 17].
Although SAMSS data have been collected since July 2002, questions on wellbeing were included from January 2014. Analysis was limited to participants aged 18 years and over $(n=5551)$. The monthly response rate (RR1) of SAMSS for this period ranged from 54.0 to $61.5($ mean $=56.9)$ [18].

Demographic covariate variables included in the analyses were sex, age, area of residence (metropolitan, rural, remote), country of birth, marital status, highest educational attainment and household money situation. Co-morbidity conditions included self-reported, medically confirmed diabetes, current asthma, cardio-vascular disease (heart attack, angina, heart disease and/or stroke), arthritis and osteoporosis. Self-reported health risk factor data included physical activity (derived on the amount of walking and moderate and vigorous activity in a 1 week period) [19], body mass index (BMI) which was derived from self-reported weight and height and recoded into four categories (underweight, normal weight, overweight and obese) [20], current smoking status, alcohol risk (derived from the number of alcoholic drinks per day and the number of times per week alcohol was consumed) [21], and inadequate daily consumption of vegetables and fruit (sufficient vegetables $=2+$ per day; sufficient fruit $=1+$ per day) [22].

The four wellbeing questions were sourced from the UK Office for National Statistics [23] and were 1) Life satisfaction (Overall, how satisfied are you with your life nowadays?); 2) Worthwhile (Overall, to what extent do you feel the things you do in your life are worthwhile?); 3) Happy yesterday (Overall, how happy did you feel yesterday?); and 4) Anxious yesterday (Overall, how anxious did you feel yesterday?). Each was scored on a scale of 0 to 10 where 0 meant "not at all" and 10 meant "completely". To score well on all four measures (indicating good wellbeing) respondents had to, for Life satisfaction, Worthwhile, and Happy yesterday, score 8 to 10 and for Anxious yesterday score 0 to $2[23,24]$.

Four questions were asked as surrogate measures of social capital. They were 'overall, do you feel that your neighbourhood is a safe place' (yes, no); 'do you think that in this neighbourhood people generally trust one another' (yes, no); 'do you feel safe in your home' (all of the time, most of the time, some of the time, none of the time) and 'I have control over the decisions that affect my life' (strongly agree, agree, neutral/don't know, disagree, strongly disagree).

SAMSS data were weighted each month by age, sex, area and probability of selection in the household to estimated resident population data of the most recent Australian Bureau of Statistics Census or estimated residential population data, so that the results were representative of the South Australian population. Probability of selection in the household was calculated on the 
Table 1 Prevalence of four individual wellbeing indicators and social capital indicators, aged 18 years and over by year, 2014-15

\begin{tabular}{|c|c|c|}
\hline & $\mathrm{n}$ & $\%(95 \% \mathrm{Cl})$ \\
\hline \multicolumn{3}{|l|}{ INDIVIDUAL WELLBEING INDICATORS } \\
\hline \multicolumn{3}{|l|}{ Life satisfaction } \\
\hline Very low (0-4) & 173 & $3.1(2.7-3.6)$ \\
\hline Low (5-6) & 515 & $9.3(8.5-10.1)$ \\
\hline Medium (7-8) & 2633 & $47.4(46.1-48.8)$ \\
\hline High (9-10) & 2186 & $39.4(38.1-40.7)$ \\
\hline Don't know, refused & 43 & $0.8(0.6-1.0)$ \\
\hline \multicolumn{3}{|l|}{ Worthwhile } \\
\hline Very low (0-4) & 108 & $1.9(1.6-2.3)$ \\
\hline Low (5-6) & 430 & $7.7(7.1-8.5)$ \\
\hline Medium (7-8) & 2374 & $42.8(41.5-44.1)$ \\
\hline High (9-10) & 2563 & $46.2(44.9-47.5)$ \\
\hline Don't know, refused & 75 & $1.3(1.1-1.7)$ \\
\hline \multicolumn{3}{|l|}{ Happy yesterday } \\
\hline Very low (0-4) & 256 & $4.6(4.1-5.2)$ \\
\hline Low (5-6) & 469 & $8.5(7.8-9.2)$ \\
\hline Medium (7-8) & 2021 & $36.4(35.2-37.7)$ \\
\hline High (9-10) & 2772 & $49.9(48.6-51.2$ \\
\hline Don't know, refused & 32 & $0.6(0.4-0.8)$ \\
\hline \multicolumn{3}{|l|}{ Anxious yesterday } \\
\hline Very high (6-10) & 484 & $8.7(8.0-9.5)$ \\
\hline High (4-5) & 422 & $7.6(6.9-8.3)$ \\
\hline Medium (2-3) & 694 & $12.5(11.7-13.4$ \\
\hline $\operatorname{Low}(0-1)$ & 3917 & $70.6(69.3-71.7)$ \\
\hline Don't know, refused & 34 & $0.6(0.4-0.9)$ \\
\hline Total & 5551 & 100.0 \\
\hline \multicolumn{3}{|l|}{ Overall Wellbeing (composite score) } \\
\hline Scoring well on all four measures & 2968 & $54.3(53.0-55.6$ \\
\hline Scoring neither well nor badly & 1764 & $32.3(31.0-33.5)$ \\
\hline Scoring badly on at least one measure & 733 & $13.4(12.5-14.3)$ \\
\hline Total & 5464 & 100.0 \\
\hline
\end{tabular}

\section{SOCIAL CAPITAL INDICATORS}

Overall, do you feel that your neighbourhood is a safe place?

$\begin{array}{lll}\text { Yes } & 5167 & 93.1(92.0-94.1) \\ \text { No, don't know } & 383 & 6.9(5.9-8.0)\end{array}$

Do you think that in this neighbourhood people generally trust one another?

$\begin{array}{lll}\text { Yes } & 4379 & 78.9(77.2-80.5) \\ \text { No, don't know } & 1172 & 21.1(19.5-22.8) \\ \text { Do you feel safe in your home? } & & \\ \text { All of the time } & 4252 & 76.6(74.9-78.2) \\ \text { Most, some or none of the time } & 1299 & 23.4(21.8-25.1)\end{array}$

Table 1 Prevalence of four individual wellbeing indicators and social capital indicators, aged 18 years and over by year, 2014-15 (Continued)

Do you agree or disagree with the following statement. I have control over decisions that affect my life

\begin{tabular}{lll} 
Strongly agree, agree & 5239 & $94.4(93.4-95.2)$ \\
Neutral, don't know & 105 & $1.9(1.5-2.5)$ \\
Disagree, strongly disagree & 206 & $3.7(3.0-4.6)$ \\
Total & 5551 & 100.0 \\
\hline
\end{tabular}

number of eligible people in the household and the number of listings in the EWP. The weights reflect unequal sample inclusion probabilities and compensate for differential non-response.

Analyses were conducted using SPSS Version 20 and Stata Version 13. Initial analyses included frequencies for the four individual and overall wellbeing (good, neither good nor poor, and poor) and social capital indicators. Univariable analyses using chi-square tests compared the overall wellbeing and the four social capital indicators, socio-demographic, risk factors and chronic conditions. Factors associated with neither good nor poor and low levels of wellbeing including risk factors, socio-economic and socio-demographic variables and concepts of social capital were assessed using multi-nominal logistic regression modelling using all three levels of wellbeing with good wellbeing as the reference category adjusting for multiple covariates. Multi-nominal logistic regression was used to simultaneously estimate odds ratios for two different comparisons: good wellbeing (reference category) versus neither good nor poor, and good wellbeing versus poor wellbeing. Model 1 adjusted for age and sex, and model 2 adjusted for age, sex, country of birth, area of residence, educational attainment, marital status, money situation and the number of adults in the household. The unadjusted model is also presented.

\section{Results}

Of the total sample $48.6 \%$ were male. Mean age was 48.7 (standard deviation 18.3) years (median 48 years). Table 1 highlights the distribution of the four individual wellbeing questions, a summary of the proportion scoring well or badly or neither on all measures, and a distribution of the six social capital related variables. In total, $54.3 \%$ of the South Australian adult population scored well on all four of the wellbeing indicators, while the range of positive responses to the social capital indicators ranged from $93.1 \%$ for safety to $50.8 \%$ for control over decisions.

The univariable distribution of the social capital indicators across the levels of wellbeing is highlighted in Table 2. In all instances the higher level of social capital corresponded with the good wellbeing category. 
Table 2 Univariable analyses of overall wellbeing by social capital indicators

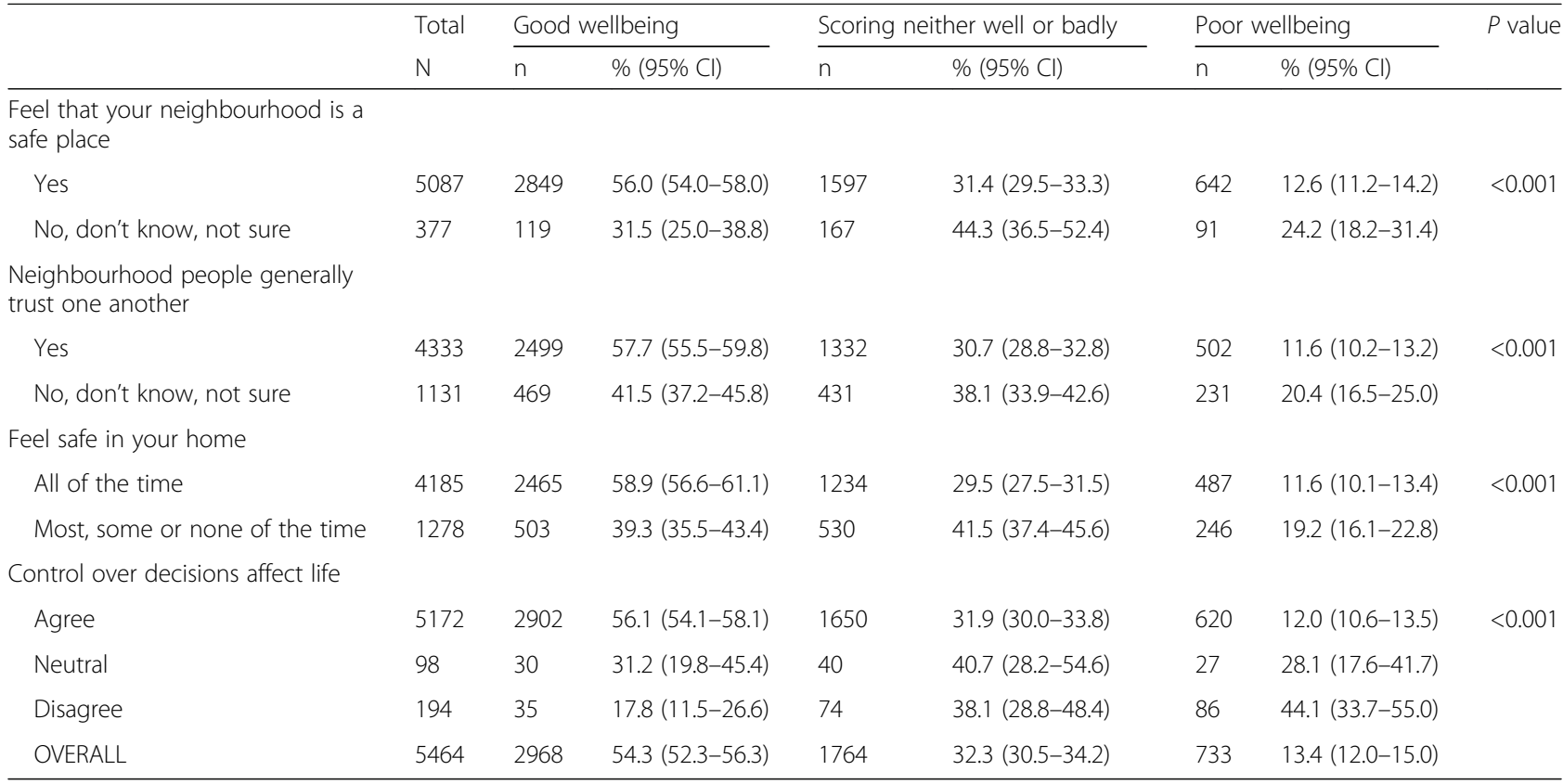

Table 3 highlights the relationship between relevant covariates and the three levels of wellbeing with all sociodemographic associations having a $p$ value of $<0.05$ except country of birth and education level. Females, older persons and those who could save had higher estimates of good wellbeing. Higher levels of poor wellbeing were seen for younger respondents, those living in the metropolitan area, the never married and those unable to save.

Table 4 highlights the relationship between chronic conditions, risk factors and wellbeing. All risk factors had a relationship except BMI. In terms of chronic conditions the only relationship was between current asthma and wellbeing.

Table 5 highlights the results of the multi-nominal modelling with higher odds ratios shown for all four social capital variables for the lowest level of wellbeing. These higher odds ratios remained even after adjusting for eight known confounders. The most marked increase in odds ratios were for the social capital variable assessing control over decisions that affect life. Those who do not have control were over 10 times more likely to have poor wellbeing.

\section{Discussion}

This analysis has detailed the distribution of wellbeing in the South Australian adult population with high levels reported for females, older persons, those living in rural areas, married and those able to save. Social capital was associated with the three levels of wellbeing with, in all cases, worse measures of social capital indicating lower levels of wellbeing. When multi-nominal level logistic regression modelling were undertaken on the four social capital variables, in each instance the unadjusted, adjusted by age and sex, and the fully adjusted models, resulted in much higher odds ratios indicating that the relationship between low levels of social capital are associated with low levels of wellbeing in the South Australian community.

The current government of South Australia aims to become the first government in the world to systematically measure and build wellbeing across different cohorts and lifespans of the society to reduce the number of people experiencing catastrophic mental illness and to improve the resilience of the population. The analysis presented here goes some way in providing avenues for improved targeting at the broad population level.

If the aim of positive psychology is to 'foster the factors that allow individuals, communities and societies to flourish' [25], based on the results of this research, the incorporation of social capital as an important factor in the endeavour to increase wellbeing, is warranted. While previous interventions based on social capital have shown positive effects on wellbeing in selected groups [2, 26, 27], positive psychology research has not yet fully incorporated social capital as an important influence in understanding how individuals and communities cope in times of stress with social capital an 'underutilized resource' in determining and increasing resilience $[7,16]$. It has been shown that social capital is at its strongest when disasters occur or when 'conflict, problems or change' are presented to communities [12]. Although much research focuses on physical/environmental disasters our results show that the close relationship between social capital and wellbeing in non-environmental 
Table 3 Univariable analyses of overall wellbeing and covariates (socio-demographic)

\begin{tabular}{|c|c|c|c|c|c|c|c|c|}
\hline & \multirow{2}{*}{$\begin{array}{l}\text { Total } \\
\mathrm{n}\end{array}$} & \multicolumn{2}{|c|}{ Good wellbeing } & \multicolumn{2}{|c|}{$\begin{array}{l}\text { Scoring neither } \\
\text { well or badly }\end{array}$} & \multicolumn{2}{|c|}{ Poor wellbeing } & \multirow[t]{2}{*}{$P$ value } \\
\hline & & $\mathrm{n}$ & $\%(95 \% \mathrm{Cl})$ & $n$ & $\%(95 \% \mathrm{Cl})$ & $n$ & $\%(95 \% \mathrm{Cl})$ & \\
\hline \multicolumn{9}{|l|}{ COVARIATES } \\
\hline \multicolumn{9}{|l|}{ Sex } \\
\hline Male & 2653 & 1357 & $51.2(48.1-54.2)$ & 923 & $34.8(31.9-37.8)$ & 373 & $14.1(11.7-16.7)$ & \multirow[t]{2}{*}{0.014} \\
\hline Female & 2811 & 1610 & $57.3(54.8-59.7)$ & 841 & $29.9(27.7-32.2)$ & 360 & $12.8(11.2-14.6)$ & \\
\hline \multicolumn{9}{|l|}{ Age group } \\
\hline $18-24$ & 551 & 230 & $41.8(35.8-48.1)$ & 226 & $40.9(34.9-47.3)$ & 95 & $17.2(13.2-22.3)$ & \multirow[t]{7}{*}{$<0.001$} \\
\hline $25-34$ & 910 & 421 & $46.3(38.8-53.9)$ & 296 & $32.5(26.1-39.6)$ & 193 & $21.2(15.4-28.5)$ & \\
\hline $35-44$ & 972 & 521 & $53.6(48.4-58.7)$ & 332 & $34.1(29.4-39.2)$ & 119 & $12.3(9.3-16.1)$ & \\
\hline $45-54$ & 1005 & 500 & $49.7(45.4-54.0)$ & 365 & $36.4(32.2-40.8)$ & 140 & $13.9(11.3-17.0)$ & \\
\hline $55-64$ & 897 & 542 & $60.4(57.6-63.3)$ & 257 & $28.6(26.1-31.4)$ & 98 & $10.9(9.3-12.8)$ & \\
\hline $65-74$ & 595 & 410 & $68.9(66.3-71.3)$ & 135 & $22.7(20.5-25.1)$ & 50 & $8.4(7.0-9.9)$ & \\
\hline $75+$ & 535 & 344 & $64.3(61.4-67.1)$ & 153 & $28.6(26.0-31.5)$ & 38 & $7.1(5.7-8.7)$ & \\
\hline \multicolumn{9}{|l|}{ Area of residence } \\
\hline Metropolitan area & 3985 & 2103 & $52.8(50.3-55.2)$ & 1304 & $32.7(30.5-35.0)$ & 577 & $14.5(12.7-16.5)$ & \multirow[t]{3}{*}{0.008} \\
\hline Rural Centres & 1409 & 825 & $58.6(55.3-61.7)$ & 435 & $30.8(27.8-34.1)$ & 149 & $10.6(8.9-12.6)$ & \\
\hline Remote Areas & 70 & 39 & $55.7(42.7-68.0)$ & 25 & $35.7(24.4-48.8)$ & 6 & $8.6(3.7-18.5)$ & \\
\hline \multicolumn{9}{|l|}{ Marital status } \\
\hline Married/De facto & 3593 & 2144 & $59.7(57.2-62.1)$ & 1058 & $29.4(27.3-31.7)$ & 391 & $10.9(9.3-12.8)$ & \multirow[t]{4}{*}{$<0.001$} \\
\hline Separated/Divorced & 368 & 170 & $46.1(41.1-51.2)$ & 142 & $38.7(33.7-43.9)$ & 56 & $15.2(12.0-19.1)$ & \\
\hline Widowed & 268 & 157 & $58.6(54.9-62.3)$ & 84 & $31.4(28.0-35.0)$ & 27 & $10(8.1-12.3)$ & \\
\hline Never married & 1227 & 493 & $40.2(35.4-45.1)$ & 478 & $39(34.4-43.8)$ & 256 & $20.9(17.2-25.1)$ & \\
\hline \multicolumn{9}{|l|}{ Country of birth } \\
\hline Australia & 4279 & 2344 & $54.8(52.6-57.0)$ & 1363 & $31.9(29.8-33.9)$ & 572 & $13.4(11.9-15.1)$ & \multirow[t]{3}{*}{0.481} \\
\hline UK and Ireland & 554 & 307 & $55.5(50.3-60.6)$ & 175 & $31.7(27.0-36.8)$ & 71 & $12.8(9.6-16.8)$ & \\
\hline Other & 630 & 316 & $50.2(43.3-57.0)$ & 225 & $35.8(29.4-42.7)$ & 88 & $14(8.9-21.4)$ & \\
\hline \multicolumn{9}{|l|}{ Educational attainment } \\
\hline Up to secondary & 2386 & 1250 & $52.4(49.7-55.1)$ & 790 & $33.1(30.5-35.8)$ & 346 & $14.5(12.6-16.7)$ & \multirow[t]{3}{*}{0.156} \\
\hline Trade, Apprenticeship, Certificate, Diploma & 1662 & 935 & $56.3(52.6-59.9)$ & 493 & $29.7(26.5-33.0)$ & 233 & $14(11.6-17.0)$ & \\
\hline Degree or higher & 1411 & 778 & $55.2(50.8-59.5)$ & 480 & $34(30.1-38.3)$ & 152 & $10.8(7.8-14.7)$ & \\
\hline \multicolumn{9}{|l|}{ Number of adults } \\
\hline 1 & 698 & 338 & $48.3(45.3-51.4)$ & 247 & $35.4(32.4-38.4)$ & 114 & $16.3(13.8-19.2)$ & \multirow[t]{3}{*}{$<0.001$} \\
\hline 2 & 2970 & 1746 & $58.8(56.3-61.3)$ & 892 & $30.0(27.7-32.5)$ & 332 & $11.2(9.7-12.9)$ & \\
\hline 3 or more & 1796 & 884 & $49.2(45.1-53.4)$ & 625 & $34.8(31.1-38.8)$ & 287 & $16.0(12.8-19.7)$ & \\
\hline \multicolumn{9}{|l|}{ Household money situation } \\
\hline $\begin{array}{l}\text { Spending more than getting to } \\
\text { some money left but spend it }\end{array}$ & 1268 & 484 & $38.2(34.5-42.0)$ & 527 & $41.6(37.7-45.6)$ & 257 & $20.3(17.4-23.5)$ & \multirow[t]{4}{*}{$<0.001$} \\
\hline Save a bit to save a lot & 3903 & 2337 & $59.9(57.5-62.2)$ & 1126 & $28.8(26.8-31.0)$ & 440 & $11.3(9.6-13.2)$ & \\
\hline Not stated & 293 & 147 & $50.1(42.2-57.9)$ & 111 & $37.8(30.2-46.1)$ & 36 & $12.1(7.6-18.9)$ & \\
\hline OVERALL & 5464 & 2968 & $54.3(52.3-56.3)$ & 1764 & $32.3(30.5-34.2)$ & 733 & $13.4(12.0-15.0)$ & \\
\hline
\end{tabular}

emergency periods, indicates an investment in social capital could assist in increasing wellbeing. Considerable resources are often invested in physical infrastructure by governments, for example with stronger building codes in preparation of a natural disaster [7]. Social capital generated in non-physical emergency times with investment in non-physical aspects of our societies, can have beneficial long-term effects. 
Table 4 Univariable analyses of overall wellbeing and covariates (health-related variables)

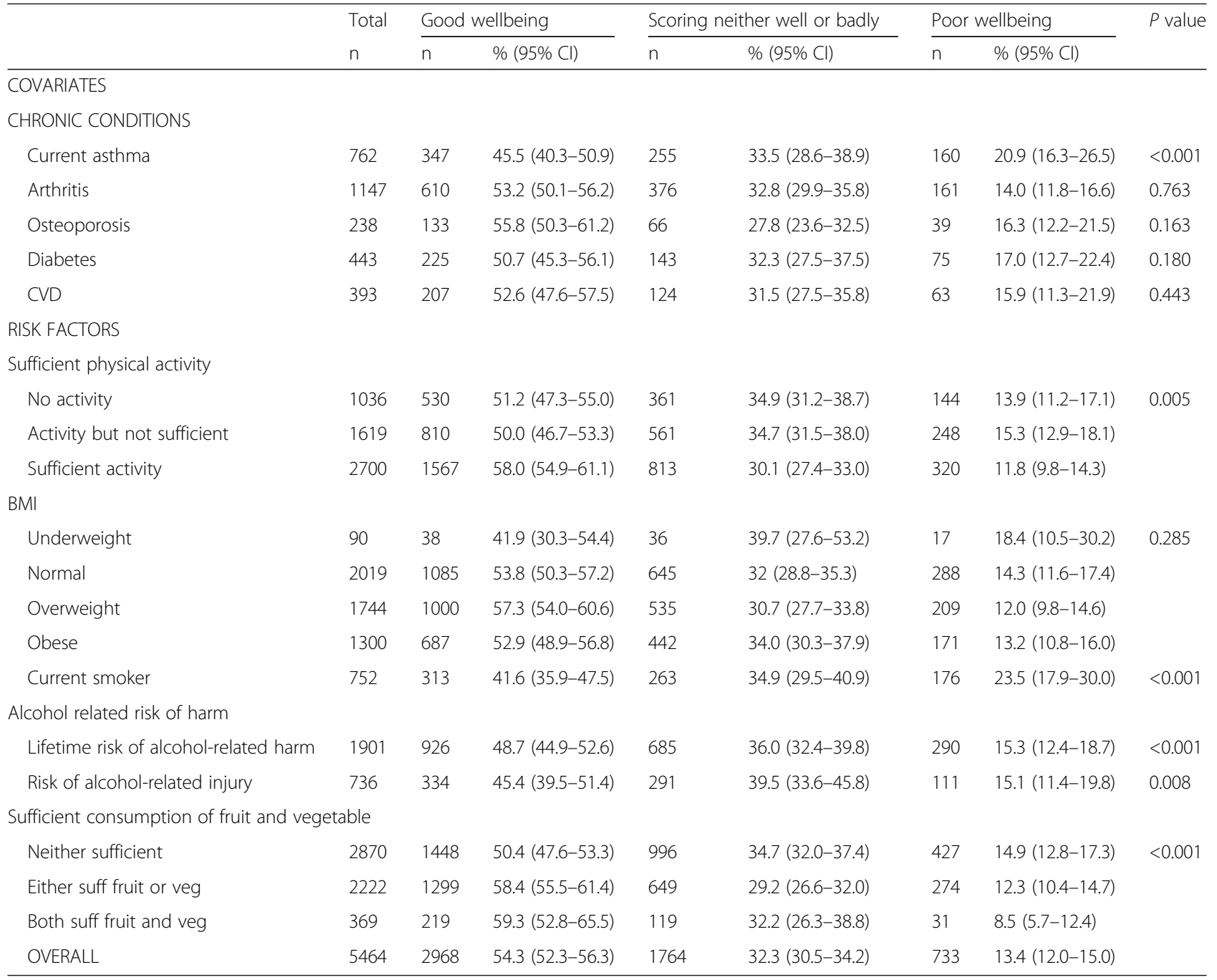

Somewhat surprising in our analysis was the lack of meaningful associations between the chronic diseases examined (except for current asthma) and the levels of wellbeing. Previous research has reported associations between positive wellbeing and a range of health outcomes including cardiovascular health [28]. A call for research into the association between wellbeing and risk factors is somewhat answered in this analysis with strong associations reported although our analysis was limited to only four risk factors [28]. Also called for, and not addressed in our research, is the role of positive health factors [28].

The strong relationship between social capital and wellbeing is not surprising given both are related to individuals and communities, each are seen as a resource or an asset for the other, both have similar pathways and relationships, both have similar confounding factors including socio-economic status, both can be invested in, both are open to development and both are measurable.
Negative critiques of wellbeing often cite the one dimensional focus on the individual associated with resilience policy approaches [29]. The broadness of what is associated under the social capital mantel complements this limiting factor. As such, possible policy interventions such as strengthening social infrastructure and community resilience should also be implemented to assist in the desired increases of wellbeing in the community.

The weaknesses associated with the study include the cross-sectional nature of the data collection such that no cause and effect can be implicated. The mode of data collection, telephone, could also be a weakness with socially desirable responses possible, and low response rates resulting in bias estimates. In addition, contention still exists in terms of the lack of conceptual clarity of social capital [7] and the correct objective and subjective way to measure social capital in the population $[1,4,11,30]$. A further weakness of our study is the limitation of the measuring of social capital to four questions. We 
Table 5 Multinomial logistic regressions of overall wellbeing by social capital indicators

\begin{tabular}{|c|c|c|c|c|c|c|}
\hline & \multicolumn{2}{|l|}{ Unadjusted } & \multicolumn{2}{|l|}{ Model 1} & \multicolumn{2}{|l|}{ Model 2} \\
\hline & OR $(95 \% \mathrm{Cl})$ & $P$ value & OR $(95 \% \mathrm{Cl})$ & $P$ value & OR $(95 \% \mathrm{Cl})$ & $P$ value \\
\hline \multicolumn{7}{|c|}{ Feeling that neighbourhood is a safe place } \\
\hline Good wellbeing (reference) & 1.00 & & 1.00 & & 1.00 & \\
\hline \multicolumn{7}{|l|}{ Scoring neither well or badly } \\
\hline Yes (feel safe place) & 1.00 & & 1.00 & & 1.00 & \\
\hline No, don't know, not sure & $2.51(1.73-3.64)$ & $<0.001$ & $2.46(1.70-3.56)$ & $<0.001$ & $2.12(1.46-3.09)$ & $<0.001$ \\
\hline \multicolumn{7}{|l|}{ Poor wellbeing } \\
\hline Yes (feel safe place) & 1.00 & & 1.00 & & 1.00 & \\
\hline No, don't know, not sure & $3.41(2.23-5.22)$ & $<0.001$ & $3.11(2.00-4.83)$ & $<0.001$ & $2.54(1.69-3.83)$ & $<0.001$ \\
\hline \multicolumn{7}{|c|}{ Neighbourhood people generally trust one another } \\
\hline Good wellbeing (reference) & 1.00 & & 1.00 & & 1.00 & \\
\hline \multicolumn{7}{|l|}{ Scoring neither well or badly } \\
\hline Yes (trust one another) & 1.00 & & 1.00 & & 1.00 & \\
\hline No, don't know, not sure & $1.73(1.39-2.14)$ & $<0.001$ & $1.69(1.36-2.10)$ & $<0.001$ & $1.52(1.22-1.90)$ & $<0.001$ \\
\hline \multicolumn{7}{|l|}{ Poor wellbeing } \\
\hline Yes (trust one another) & 1.00 & & 1.00 & & 1.00 & \\
\hline No, don't know, not sure & $2.45(1.79-3.34)$ & $<0.001$ & $2.35(1.73-3.18)$ & $<0.001$ & $2.00(1.45-2.76)$ & $<0.001$ \\
\hline \multicolumn{7}{|l|}{ Feeling safe in own home } \\
\hline Good wellbeing (reference) & 1.00 & & 1.00 & & 1.00 & \\
\hline \multicolumn{7}{|l|}{ Scoring neither well or badly } \\
\hline All of the time (feel safe) & 1.00 & & 1.00 & & 1.00 & \\
\hline Most, some or none of the time & $2.11(1.71-2.59)$ & $<0.001$ & $2.15(1.75-2.65)$ & $<0.001$ & $2.10(1.71-2.59)$ & $<0.001$ \\
\hline \multicolumn{7}{|l|}{ Poor wellbeing } \\
\hline All of the time (feel safe) & 1.00 & & 1.00 & & 1.00 & \\
\hline Most, some or none of the time & $2.47(1.86-3.28)$ & $<0.001$ & $2.47(1.86-3.29)$ & $<0.001$ & $2.37(1.76-3.19)$ & $<0.001$ \\
\hline \multicolumn{7}{|l|}{ Control over decisions affect life } \\
\hline Good wellbeing (reference) & 1.00 & & 1.00 & & 1.00 & \\
\hline \multicolumn{7}{|l|}{ Scoring neither well or badly } \\
\hline Agree (have control over decisions) & 1.00 & & 1.00 & & 1.00 & \\
\hline Neutral & $2.30(1.17-4.51)$ & 0.016 & $2.39(1.21-4.72)$ & 0.012 & $2.12(1.06-4.23)$ & 0.034 \\
\hline Disagree & $3.76(2.16-6.54)$ & $<0.001$ & $3.71(2.12-6.49)$ & $<0.001$ & $3.26(1.86-5.72)$ & $<0.001$ \\
\hline \multicolumn{7}{|l|}{ Poor wellbeing } \\
\hline Agree (have control over decisions) & 1.00 & & 1.00 & & 1.00 & \\
\hline Neutral & $4.22(2.02-8.81)$ & $<0.001$ & $4.74(2.28-9.86)$ & $<0.001$ & $4.12(1.99-8.51)$ & $<0.001$ \\
\hline Disagree & $11.58(6.41-20.93)$ & $<0.001$ & $11.78(6.69-20.76)$ & $<0.001$ & $9.81(5.64-17.06)$ & $<0.001$ \\
\hline
\end{tabular}

$\mathrm{OR}$ - odds ratio; $\mathrm{Cl}$ - confidence interval

Model 1: adjusted by sex and age

Model 2: adjusted by sex, age and other socio-demographic and socio-economic indicators (country of birth, area of residence, educational attainment, marital status, money situation, number of adults)

acknowledge that our measure of social capital is a broad brush approach and not specifically encompassing the different types of social capital such as bonding, bridging and linking $[4,10]$. We also acknowledge that our wellbeing questions are somewhat limited in scope, limited by the time on the telephone, and that well-developed wellbeingrelated questionnaires exist [31-33].
Notwithstanding, the strengths of this study include the large sample size, the representative population and the value of adding, as called for by others, broad population research in the positive psychology and wellbeing arenas $[14,33]$. Also a strength is the use of an extensive list of confounders in the multivariable analyses. As highlighted by Harphan et al. [9], the desired confounders that should 
be incorporated into any social capital analysis include socio-economic status, education, gender and number of people per household all of which we have adjusted for in our analysis. The use of an on-going surveillance system as the collection mode, with consistent use of questions and methods, will allow for population groups to be monitored over time and evaluations to be assessed within the population and priority groups.

\section{Conclusion}

This research has highlighted the relationship between wellbeing, resilience and social capital showing how inter-related they are, how important the associations are and highlighting areas for possible increased policy focus. As argued by Bernier and Meinzen-Dick [16], this relationship has been underexplored. The positive wellbeing attributes of individuals and their relationship to others in their community are important considerations. The work being undertaken in South Australia to improve individual and community wellbeing will continue to be evaluated so that the value of prevention rather that treatment can be assessed.

\section{Acknowledgments \\ SAMSS is owned by Department for Health and Ageing, South Australia, Australia. All collected source data are maintained and managed by Population Research and Outcome Studies, The University of Adelaide. The opinions expressed in this work are those of the authors and may not represent the position or policy of SA Department for Health and Ageing.}

\section{Funding}

No specific funding was obtained for this work.

\section{Availability of data and materials}

Data available on request from author.

\begin{abstract}
Authors' contributions
AWT: Major contribution to the design of the study, acquisition of the data, interpretation of data; and drafting the manuscript. GK: Made contribution to concept and design of study, interpretation of data and reviewed and edited the draft manuscript. EDG: Made contribution to concept and design of study, acquisition of data, analysis and interpretation of data, and reviewed and edited the draft manuscript. DK: Made contribution to concept and design of study, interpretation of data and reviewed and edited the draft manuscript. TM: Made contribution to concept and design of study, acquisition of data, analysis and interpretation of data, and reviewed and edited the draft manuscript. NH: Made contribution to concept and design of study, interpretation of data, and reviewed and edited the draft manuscript. KJB: Made contribution to concept and design of study, acquisition of data, analysis and interpretation of data, and reviewed and edited the draft manuscript. JL: Made contribution to concept and design of study, interpretation of data and reviewed and edited the draft manuscript. All authors: Gave final approval of the version to be published and agreed to be accountable for all aspects of the work in ensuring that questions related to the accuracy or integrity of any part of the work are appropriately investigated and resolved.
\end{abstract}

\section{Ethics approval and consent to participate}

Ethics clearance was gained from the South Australian Department of Health and Ageing Human Research Ethics Committee (436.02.2014). All procedures performed in studies involving human participants were in accordance with the ethical standards of the institutional and/or national research committee and with the 1964 Helsinki declaration and its later amendments or comparable ethical standards. Informed consent was obtained from all individual participants included in the studies.
Consent for publication

Not applicable.

\section{Competing interests}

All authors declare that they have no competing interest.

\section{Publisher's Note}

Springer Nature remains neutral with regard to jurisdictional claims in published maps and institutional affiliations.

\section{Author details}

${ }^{1}$ Population Research \& Outcome Studies, Discipline of Medicine, The University of Adelaide, Adelaide, South Australia, Australia. ${ }^{2}$ Wellbeing and Resilience Centre, South Australian Health and Medical Research Institute (SAHMRI), Adelaide, Australia. ${ }^{3}$ What Works Centre for Wellbeing, London, UK. ${ }^{4}$ CQUniversity, Appleton Institute, School of Human, Health \& Social Sciences, Wayville, South Australia, Australia.

Received: 10 January 2017 Accepted: 22 June 2017

Published online: 03 July 2017

\section{References}

1. Berry HL, Welsh JA. Social capital and health in Australia: an overview from the household, income and labour dynamics in Australia survey. Soc Sci Med. 2010;70:588-96. doi:10.1016/j.socscimed.2009.0112.

2. Bolier B, Haverman M, Westerhof GJ, Riper H, Smit F, Bohlmeijer E. Positive psychology interventions: a meta-analysis of randomized controlled studies. BMC Public Health. 2013;13:119. doi:10.1186/1471-2458-13-119.

3. Mitchell J, Vella-Brodrick D, Klein B. Positive psychology and the internet: a mental health opportunity. Electronic Journal of Applied Psychology. 2010; 6(2):30-41.

4. Almedon AM. Social capital and mental health: an interdisciplinary review of primary evidence. Soc Sci Med. 2005;61:943-64. doi:10.1016/j.socscimed. 2004.12.025.

5. Bonanno GA, Westphal M, Mancini AD. Resilience to loss and potential trauma. Annu Rev Clin Psychol. 2011;7:511-35. doi:10.1146/annurev-clinpsy032210-104526.

6. Cornum R, Matthews MD, Seligman ME. Comprehensive soldier fitness: building resilience in a challenging institutional context. Am Psychol. 2011; 66(1):4.

7. Aldrich DP, Meyer MA. Social capital and community resilience. Am Behav Sci. 2015;59(2):254-69. doi:10.1177/0002764214550299.

8. Seligman ME. Building the state of wellbeing: a strategy for South Australia. Adelaide: Government of South Australia; 2013.

9. Harphan T, Grant E, Thomas E. Measuring social capital within health surveys: key issues. Health Policy \& Planning. 2002;17(1):106-11.

10. Poortinga W, Suffolk C. (2011). Community resilience and wellbeing in Wales: A secondary analysis of the 2007 and 2009 citizenship survey. Cardiff University. Downloaded from ???

11. Szreter S, Woolcock M. Health by association? Social capital, social theory and the political economy of public health. Int J Epidemiol. 2003;33:1-18. doi:10.1093/ije/dyh013.

12. Australian Bureau of Statistics (ABS). (2002). Social capital and social wellbeing. Discussion Paper. Commonwealth of Australia. Downloaded from http://www.abs.gov.au/websitedbs/D3110122.NSF/6ead87599a9a3b0bca256 eaf00836eb9/150bcb152250ddcfca256c220080ba47!OpenDocument

13. Taylor A, Dal GE. Chronic disease and risk factor surveillance using the SA Monitoring and surveillance system (SAMSS) - history, results and future challenges. Public Health Bull South Aust. 2008:5(3):17-21. Retrieved from http://pandora.nla.gov.au/pan/87601/20090417-1005/www.dh.sa.gov.au/ pehs/publications/0811- PHB-Epidem-Public-Health.pdf.

14. Kobau R, Seligman ME, Peterson C, Diener E, Zack MM, Chapman D, Thompson W. Mental health promotion in public health: perspectives and strategies from positive psychology. Am J Public Health. 2011;101(8):e1-9. doi:10.2105/AJPH.2010.83.

15. Seligman ME, Park N, Steen TA. A balanced psychology and a full life. Philosophical Transactions of the Royal Society London. 2004;359:1379-81. doi:10.1098/rstb.2004.1513.

16. Bernier Q, Meinzen-Dick R. Resilience and social capital. International Food Policy Research Institute: Conference paper - Building resilience for food; 2014. Downloaded from www.ifpri.org/publication/resilience-and-social-capital. 
17. Population Research and Outcome Studies (PROS). South Australian Monitoring and surveillance system (SAMSS) technical report. Report 1/04, 2004: survey methodology. South Australia: SA Department of Health Adelaide; 2004.

18. American Association for Public Opinion Research (AAPOR). (2011). Standard definitions: final dispositions of case codes and Outcome rates for surveys, 7th Edition. 7th edition ed. Deerfield, Illinois, USA: AAPOR; 2011.

19. Australian Government. Australia's physical activity and sedentary behaviour guidelines. Department of Health and Aged Care. Canberra; 2005. Available at http://www.health.gov.au/internet/main/publishing.nsf/Content/healthpubhlth-strateg-phys-act-guidelines.

20. World Health Organization (WHO). BMI classification. Geneva, Switzerland; 2010. Available from: http://www.who.int/nutrition/publications/obesity/ WHO_TRS_894/en/.

21. NHMRC (National Health and Medical Research Council). Australian Guidelines to reduce health risks from drinking alcohol Commonwealth of Australia; 2009. Available at https://www.nhmrc.gov.au/guidelines-publications/ds10.

22. NHMRC (National Health and Medical Research Council). The dietary Guidelines for Australians; 2005. Downloaded from https://www.nhmrc.gov.au/ guidelinespublications/n29-n30-n31-n32-n33-n34.

23. Evans, J., Macrory, I., \& Randall, C. (2015). Measuring National Well-Being: life in the UK, 2015: Office for National Statistics.

24. Abdallah S, Shah S. Well-being patterns uncovered: an analysis of UK data. United Kingdom: The new economics foundation; 2012. http://b.3cdn.net/ nefoundation/60770a0ad7bce041e2_gcm6b0nfk.pdf.

25. Fredrickson BL. The Role of Positive Emotions in Positive Psychology. The Broaden-and-Build Theory of Positive Emotions. Am Psychol. 2001;56(3):218-26.

26. Mongrain M, Anselmo-Matthews T. Do Positive Psychology Exercises Work? A Replication of Seligman et al. J Clin Psychol. 2012;68:382-9.

27. Seligman MEP, Steen TA. Positive Psychology Progress. Empirical Validation of Interventions. Am Psychol. 2005;60(5):410-21. doi:10.1037/0003-006x.60.5410.

28. Boehm JK, Kubzansky LD. The heart's content: the association between positive psychological wellbeing and cardiovascular health. Psychol Bull. 2012;138(4):655-91. doi:10.1037/a0027448.

29. Allmark $P$, Bhanbhro $S$, Chrisp T. An argument against the focus on Community Resilience in Public Health. BMC Public Health. 2014;14:62. doi:10.1186/1471-2458-14.62.

30. Altschuler A, Somkin CP, Adler NE. Local services and amenities, neighborhood social capital, and health. Soc Sci Med. 2004;59(6):1219-29. doi:10.1016/j.socscimed.2004.01.008.

31. Kern ML, Waters LE, Adlea A, White MA. A multidimensional approach to measuring wellbeing in students: Application of the PERMA framework. J Posit Psychol. 2015;10(3):262-71. doi:10.1080/17439760.2014.936962.

32. Forgeard MJC, Jayawickreme E, Kern ML, Seligman MEP. Doing the right thing: Measuring wellbeing for public policy. Int J Wellbeing. 2001;1(1):79-106. doi:10.5502/ijw.v1.1.15.

33. OECD. OECD Guidelines on measuring subjective wellbeing. OECD Publishing; 2013. ISBN 978-92-64-19165-5. http://dx.doi.org/10.1787/9789264191655-en.

\section{Submit your next manuscript to BioMed Central and we will help you at every step:}

- We accept pre-submission inquiries

- Our selector tool helps you to find the most relevant journal

- We provide round the clock customer support

- Convenient online submission

- Thorough peer review

- Inclusion in PubMed and all major indexing services

- Maximum visibility for your research

Submit your manuscript at www.biomedcentral.com/submit 